\title{
An assessment of composite repair system in offshore platform for corroded circumferential welds in super duplex steel pipe
}

\author{
S. de Barros, S. Budhe, M.D. Banea \\ Federal Center of Technological Education in Rio de Janeiro - CEFET/RJ, Rio de Janeiro/RJ, Brazil \\ silvio.debarros@gmail.com, bttp://orcid.org/0000-0002-2520-569X \\ sandipii@gmail.com \\ mdbanea@gmail.com, bttp://orcid.org/0000-0002-8378-2292
}

N.R.F. Rohem

Instituto Federal Fluminense, Rio de Janeiro, Brazil

neyrohem@gmail.com

\section{E.M. Sampaio}

Universidade do Estado do Rio de Janeiro-UERJ, RuaBonfim, 25. Nova Friburgo, 28625-570 Rio de Janeiro, Brazil edu.msampaio@gmail.com

\author{
V.A. Perrut \\ Research and Development Center, CENPES, Petróleo Brasileiro S.A. - PETROBRAS, Rio de Janeiro, Brazil \\ Metallurgical and Materials Engineering Department, Federal University of Rio de Janeiro, Brazil \\ vperrut@petrobras.com.br
}

L.D.M. Lana

Research and Development Center, CENPES, Petróleo Brasileiro S.A. - PETROBRAS, Rio de Janeiro, Brazil luiz.lana@petrobras.com.br

\footnotetext{
ABSTRACT. The main aim of this study is to assess the effectiveness of a composite repair system in severely corroded circumferential welds in super duplex stainless steel pipes as a preventive measure against the premature corrosion damage at the welds. Artificial defects were fabricated on the super duplex steel tube in order to reproduce the localized corrosion damage defects found in real welded joints. Three kinds of through thickness defects were considered: $25 \%, 50 \%$ and $96 \%$ of the perimeter of the pipe. The performance of the repaired pipe was assessed by hydrostatic tests as per ISO 24817 standard. The results showed that the composite repair system can sustain the designed failure pressure even for the pipe damaged with throughwall defect up to $96 \%$ of the perimeter of the pipe. Hence, the composite
}

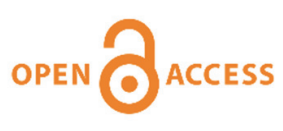

Citation: de Barros, S., Budhe, S., Banea, M.D., Rohem, N.R.F., Sampaio, E.M., Perrut, V.A., Lana, L.D.M., An assessment of composite repair system in offshore platform for corroded circumferential welds in super duplex steel pipe, Frattura ed Integrità Strutturale, 44 (2018) 151-160.

Received: 15.03 .2018

Accepted: 18.03.2018

Published: 01.04.2018 
repair system can be used as a preliminary tool to protect the unexpected or premature failure at the welds and maintain an adequate level of mechanical strength for a given operating pressure. This composite repair system can assure that the pipe will not leak until a planned maintenance of the line. Nevertheless, further work is still desirable to improve the confidence in the long-term performance of bonded composite.

KEYWORDS. Pipe repair; Super duplex steel; Corrosion; Composites; Hydrostatic tests; Offshore.
Copyright: (C) 2018 This is an open access article under the terms of the CC-BY 4.0, which permits unrestricted use, distribution, and reproduction in any medium, provided the original author and source are credited.

\section{INTRODUCTION}

$\mathrm{S}$ teel pipelines are commonly used for transportation of fluids over long distance due to its good mechanical properties. However, it becomes corroded as it is exposed to harsh environment without any protection, which causes frequent repair of system or replacement and it ultimately imposes more cost [1-4]. Traditionally pipelines with severe corrosion problems have to either be repaired using welding technique or replaced by new ones. In both cases, the offshore unit needs to be shut down as it involves hot work (welding), which can be dangerous, resulting in huge economic loss and delay in productions [4-6].

Nowadays, the super duplex stainless steel pipes are increasingly used due to an excellent resistance to corrosion in harsh environments combined with good mechanical properties. However, despite the high resistance to corrosion, the welding process of this material is not simple and is susceptible to corrosion, if the welding parameters are not properly controlled [7-9]. Thus, it is possible to have duplex or super duplex steel piping assemblies with significant corrosion damage at the welds (Fig.1).

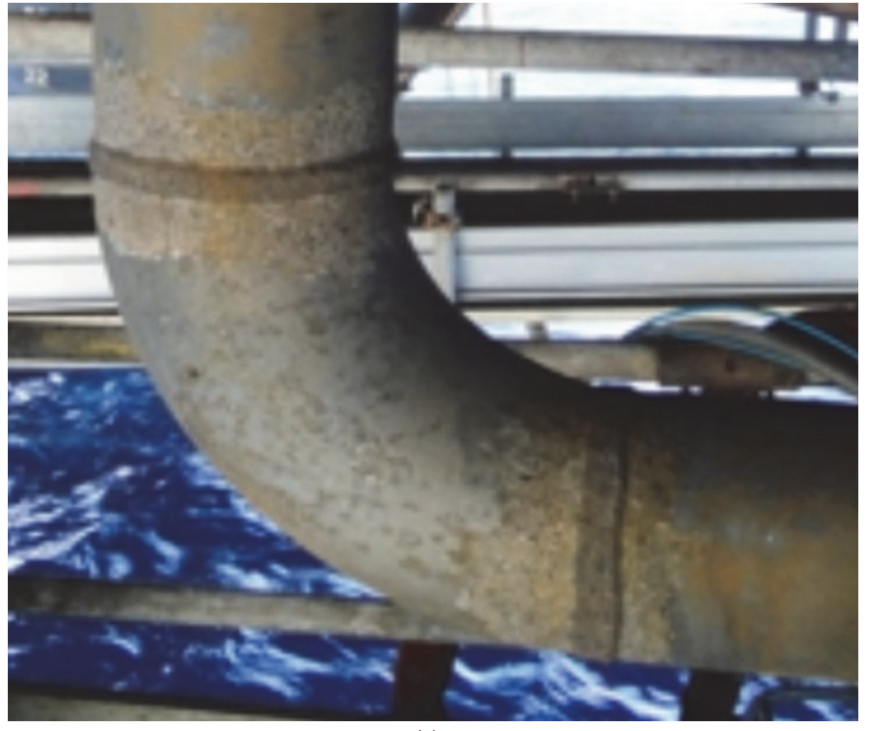

(a)

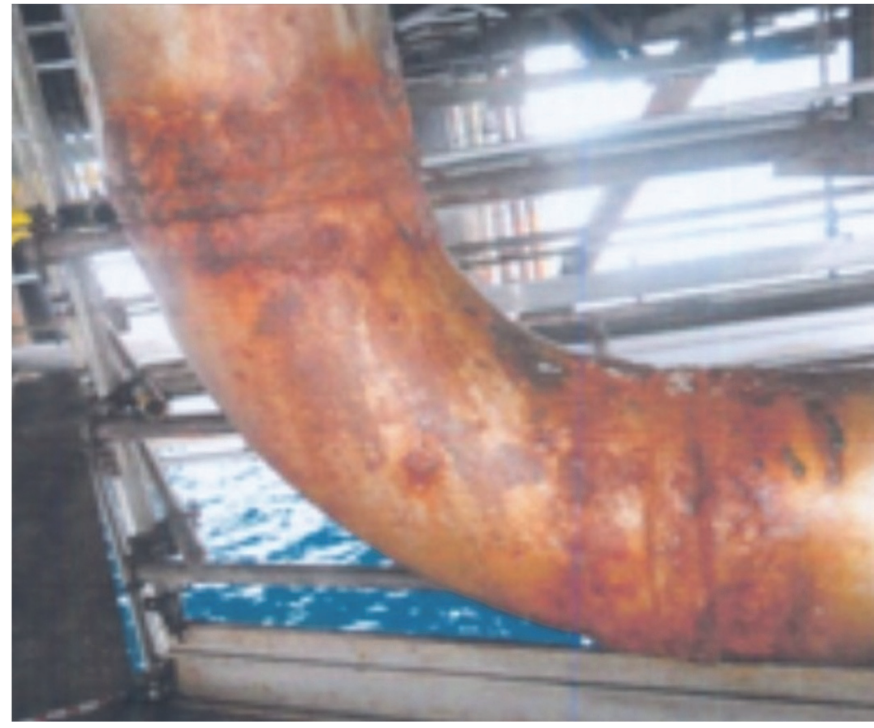

(b)

Figure 1: Super duplex steel piping assembly: (a) uncorroded welds (b) corroded welds.

The unequal wall thickness welded joint often suffers more serious corrosion damage than the other parts of the pipe. More stress concentration at the joint due to welding is generated, as it involves metal melting and solidification, which change the material properties between the weld zone, heat affected and base metal zone [10]. Hence, failures at welded joints of metal pipes have begun to occur more frequently, causing more repair and requiring maintenance, which adds more cost to the operators [11]. 
A new repair method using a polymer based composite system has been developed for the damaged part of the offshore unit. Nowadays, it is possible to repair pipelines in short time without interrupting the routine operation and without increasing risk for explosion as it involves a cold work process and it prevents corrosion [12-15].

ASME PCC-2 and ISO 24817 composite repair standards were developed to provide the guidelines for designing a reliable repair of metallic pipelines, which guarantees structural integrity [16,17]. These standards cover a wide range of defects, mainly through wall and wall loss defect. Continuous research is ongoing on the material characterization and design analysis of composite repair system for an assurance of structural integrity [18-20]. Da Costa et al analyzed an epoxy repair system for metallic pipelines undergoing elastic or inelastic deformations with localized corrosion damage [21]. A simple methodology was proposed to estimate the failure pressure of thin and thick walled metallic pipelines with arbitrary localized corrosion damage [22-25]. Hydrostatic tests performed in different laboratories were used to validate the proposed methodology, showing that a simple expression allows estimating a lower bound for the failure pressure [25, 26].

The repair of corroded pipelines with fiber reinforced composite materials is a well-developed practice in the oil and gas transportation industry [27-29]. However, there are many parameters such as composite material properties, composite repair thickness, geometry, etc., which influence the life of repair structures [28, 29]. Therefore, it is important to know whether a composite material used in a structural application will continue to perform satisfactorily over the lifetime of the structure under real environmental condition. This includes the material's ability to both sustain a load and resist further deformation while subjected to harsh environmental conditions, such as elevated temperatures, chemicals, or moisture.

The main motivation of this study is to rehabilitate corroded circumferential weld pipes using a polymer-based composite in offshore platforms. The objective is to assure an adequate application of a composite sleeve in such a way that the pipe will not leak after repair until a planned maintenance. This methodology is conceived to adequately repair weld joints presenting damage through-thickness defect up to $96 \%$ of the perimeter of the pipe.

\section{EXPERIMENTAL PROCEDURE}

$\mathrm{I}$ $\mathrm{n}$ the present study different percentage of the perimeter through-thickness defects in metallic pipes were analyzed by performing hydrostatic tests on the specially fabricated pipe specimens.

\section{Materials}

Super duplex stainless steel tubes ASTM 2507 were used for the study. Super duplex stainless steel pipes are increasingly used in offshore platform due to the improved mechanical properties in addition to the excellent resistance against corrosion. The basic properties of super duplex stainless steel pipe material are Young's Modulus $\mathrm{E}_{\mathrm{p} i p e}=200 \mathrm{GPa}$; yield stress $\sigma_{\mathrm{y}}=550 \mathrm{MPa}$ and ultimate strength $\sigma_{\mathrm{u}}=750 \mathrm{MPa}$.

A bidirectional fabric of glass fibers oriented at $0^{\circ}$ in its longitudinal direction and $90^{\circ}$ to the transverse direction was used. The resin-woven proportion used was 2:1. The fabric should have approximately $66 \%$ of their fibers oriented in its longitudinal direction (circumferential direction of the pipe) and 34\% in the transverse direction (axial pipe direction).

A bi-component epoxy resin, PIPEFIX developed by Novatec Ltd (Nova Friburgo RJ, Brazil) and qualified by Petrobras Research and Development Center (CENPES) in accordance with ISO 24817 standard [17] was used. The curing time was 2 hours at room temperature. The properties of the constituent materials used in the hand lay-up process supplied by the manufacturer are presented in Tab.1.

\begin{tabular}{lcc}
\hline Materials & Material Density $\left(\mathrm{g} / \mathrm{cm}^{3}\right)$ & Young's modulus $(\mathrm{GPa})$ \\
Fiber glass & 2.55 & 72 \\
Epoxy resin & 1.38 & 3.5 \\
\hline
\end{tabular}

Table 1: Material properties used for manual lamination.

In order to obtain the material properties of the composite laminate, tensile test specimens were prepared as per the standard ASTM D3039 [30]. The specimens were tested in a universal testing machine (Shimadzu AGI $100 \mathrm{kN}$ ) at room temperature and relative humidity of $50 \% \pm 10 \%$. Five specimens were tested at a crosshead speed of $2 \mathrm{~mm} / \mathrm{min}$. Fig. 2 shows the tensile test setup with an extensometer (model SG50-50 Shimadzu) attached to the specimen. The load-displacement curve of 
specimens obtained from was recorded. The Young's modulus and tensile strength values in both directions (circumferential and axial) were calculated and the results can be seen in Tabs. 2 and 3, respectively. The average circumferential elasticity modulus of the laminate is $\mathrm{E}_{\theta}=16.60 \mathrm{GPa}$, the axial elasticity modulus is $\mathrm{E}_{\mathrm{z}}=9.52 \mathrm{GPa}$ and the Poisson's ratio is $\nu=$ 0.1326 .

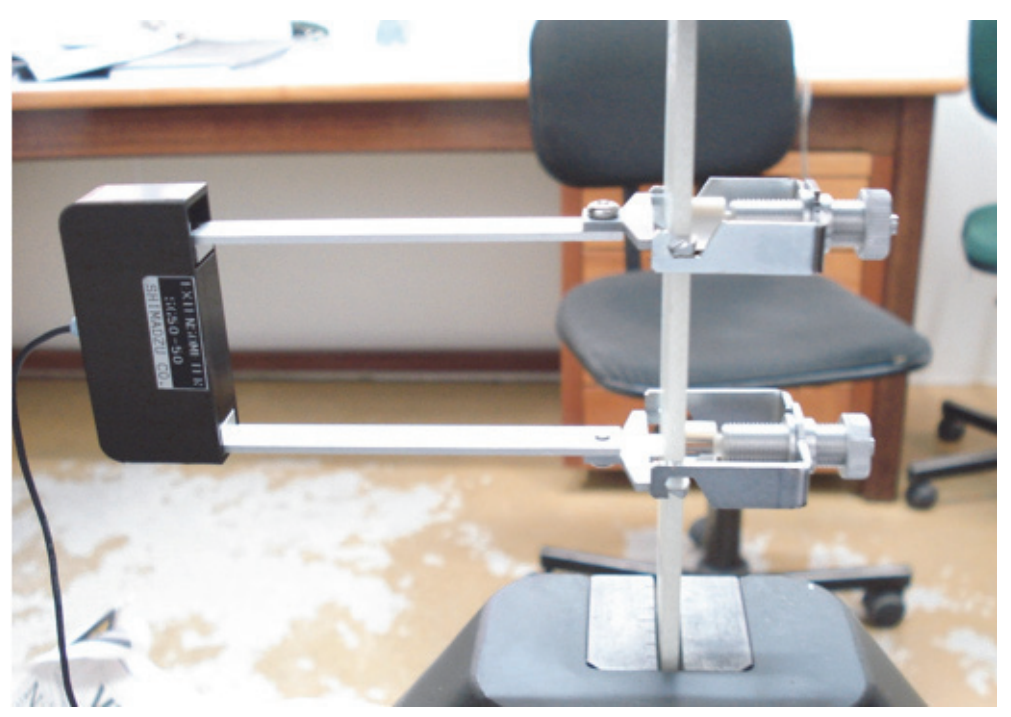

Figure 2: Tensile test set up with an extensometer

\begin{tabular}{cccccc}
\hline Specimen & $\begin{array}{c}\text { Thickness } \\
(\mathrm{mm})\end{array}$ & $\begin{array}{c}\text { Width } \\
(\mathrm{mm})\end{array}$ & $\begin{array}{c}\text { Gauge Length } \\
(\mathrm{mm})\end{array}$ & $\begin{array}{c}\text { Max. tension } \\
(\mathrm{MPa})\end{array}$ & $\begin{array}{c}\text { Young's } \\
\text { modulus }(\mathrm{GPa})\end{array}$ \\
1 & 2.0 & 19.0 & 50.00 & 355.45 & 17.11 \\
2 & 2.0 & 19.1 & 50.00 & 345.66 & 16.43 \\
3 & 2.0 & 19.1 & 50.00 & 350.34 & 16.66 \\
4 & 2.0 & 19.2 & 50.00 & 336.70 & 16.72 \\
5 & 2.0 & 19.2 & 50.00 & 350.57 & 16.57 \\
\hline & & & Average & 347.74 & 16.60 \\
& & & Standard deviation & 7.08 & 0.25 \\
\hline
\end{tabular}

Table 2: Tensile test results of composite laminate along circumferential direction.

\begin{tabular}{cccccc}
\hline Specimen & $\begin{array}{c}\text { Thickness } \\
(\mathrm{mm})\end{array}$ & $\begin{array}{c}\text { Width } \\
(\mathrm{mm})\end{array}$ & $\begin{array}{c}\text { Gauge Length } \\
(\mathrm{mm})\end{array}$ & $\begin{array}{c}\text { Max. tension } \\
(\mathrm{MPa})\end{array}$ & $\begin{array}{c}\text { Young's } \\
\text { modulus (GPa) }\end{array}$ \\
1 & 2.0 & 19.0 & 50.00 & 154.31 & 8.93 \\
2 & 1.7 & 19.0 & 50.00 & 186.09 & 10.83 \\
3 & 1.9 & 19.2 & 50.00 & 165.02 & 8.74 \\
4 & 1.8 & 19.1 & 50.00 & 165.41 & 9.57 \\
5 & 1.8 & 19.2 & 50.00 & 185.73 & 9.53 \\
\hline & & Average & 171.31 & 9.52 \\
& & & Standard deviation & 14.05 & 0.82 \\
\hline
\end{tabular}

Table 3: Tensile test results of composite laminate along axial direction. 


\section{Methods}

The hydrostatic tests were designed to evaluate the performance of composite repair system on superduplex tube test specimens that have a through wall defect simulating a weld bead failure.

The test specimens were fabricated with sections of super duplex stainless steel tubes with a diameter of 4" (114.3 mm) and a thickness of $3.05 \mathrm{~mm}$ and axial length of $700 \mathrm{~mm}$. The damage that simulates the weld bead failure is in the central region of the tube section. The artificial defects aim to reproduce localized corrosion damage in the heat-affected zone found in real welded joints. Three kinds of artificial through-thickness defects were considered as follows:

1) $25 \%$ of the perimeter through-thickness defects were fabricated and the size of defects is $90 \mathrm{~mm} \times 5 \mathrm{~mm}$. (Fig.3a).

2) $50 \%$ of the perimeter through-thickness defects were fabricated. Two defects of approximately $90 \mathrm{~mm} \times 5 \mathrm{~mm}$ were machined. Among the defects, a $5 \mathrm{~mm}$ section was left in order to guarantee the spacing and to keep the tube attached (Fig.3b).

3) $96 \%$ of the perimeter through-thickness defects were fabricated. Two damages of approximately $90 \mathrm{~mm} \times 5 \mathrm{~mm}$ and a single damage of approximately $180 \mathrm{~mm} \times 5 \mathrm{~mm}$ were machined (stretches of $5 \mathrm{~mm}$ were left between the defects in order to guarantee the spacing and keep the tube attached (Fig.3c)).

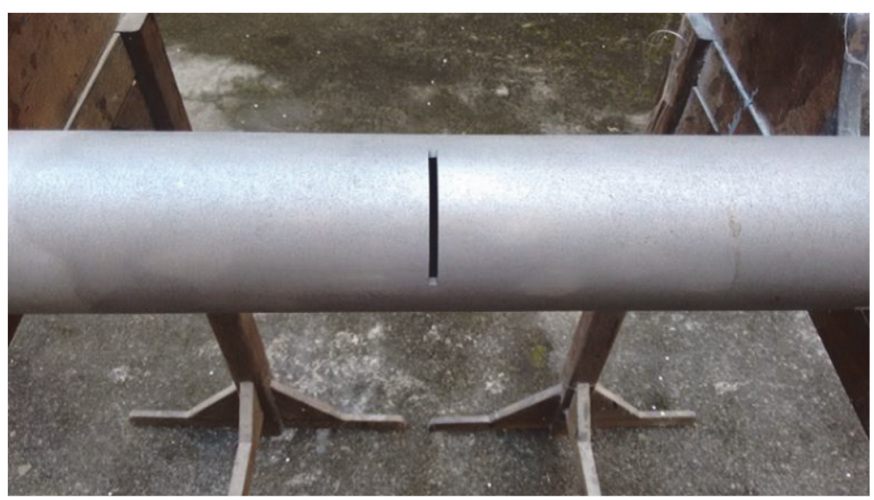

(a)

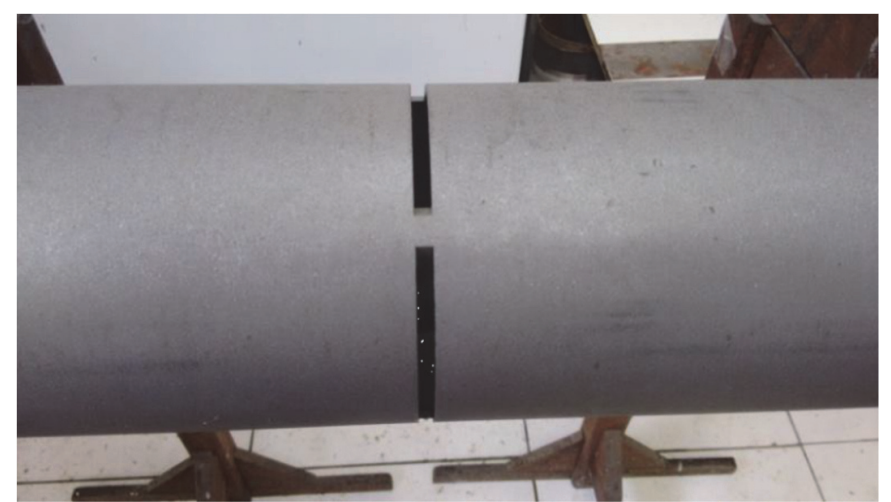

(b)

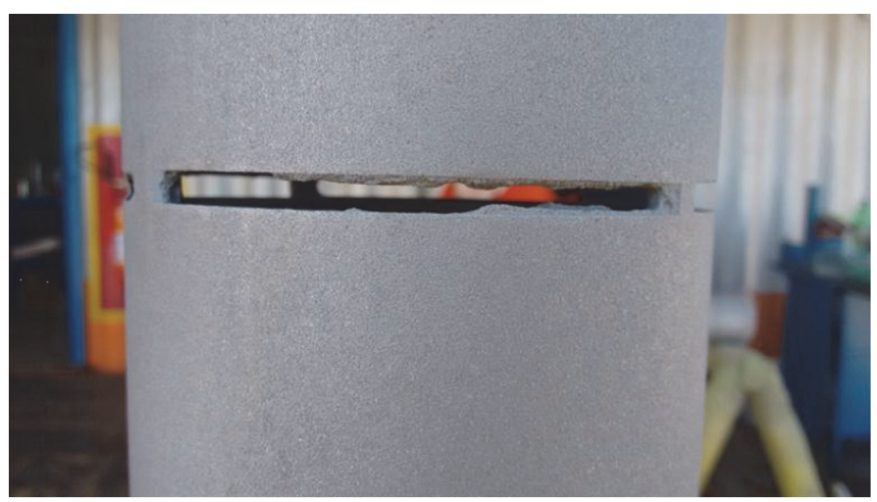

(c)

Figure 3: Through thickness defect: (a) in $25 \%$ of the perimeter (b) in $50 \%$ of the perimeter (c) in $96 \%$ of the perimeter.

\section{Surface Preparation}

In order to achieve the desired level of roughness value for better adhesion between the machined defect surface and the selected adhesive, the surface preparation was carried out [31]. A recyclable abrasive blasting media was used to achieve a white metal appearance and to remove dust particle and the oxide layer. For surface treatment, an abrasive blasting with the sponge-jet was used. Roughness parameters, namely average roughness $\left(\mathrm{R}_{\mathrm{a}}\right)$, maximum roughness $\left(\mathrm{R}_{\mathrm{z}}\right)$, root mean square $\left(\mathrm{R}_{\mathrm{q}}\right)$ and maximum height of the profile $\left(\mathrm{R}_{\mathrm{t}}\right)$ were used to evaluate the surface roughness of the tube specimen [32]. Measurements were performed in different areas (five points), near to the defect region of the tube (Tab.4).

\section{Specimen Preparation}

Pipes with $114.3 \mathrm{~mm}$ (4") diameter and wall thickness of $3.05 \mathrm{~mm}$ with a machined through-thickness defects $(25 \%, 50 \%$ and $96 \%$ of the perimeter) section were closed with stainless steel flanges using welding process. A machined (defect) section 
of super duplex stainless steel tube was cleaned with acetone to remove dust and foreign particles and then a layer of primer NVT was applied, as shown in Fig.4. The defect pipe is wrapped with concentric layers of a fiberglass tape with laminating resin (32 layers with approximately $0.298 \mathrm{~mm}$ thickness each). The calculation of composite repair thickness was based on the ISO 24817 standard. The calculated composite repair thickness was $9.5 \mathrm{~mm}$. The repair system used PIPEFIX, adhesive and 32 turns of the laminate being applied with an axial length of $300 \mathrm{~mm}$. Each laminate turn was followed by a layer of resins and pressed with a metallic roller for compact, as shown in Fig. 5.

\begin{tabular}{cccccc}
\hline Tube specimen & Readings & $\mathrm{R}_{\mathrm{a}}[\mu \mathrm{m}]$ & $\mathrm{R}_{\mathrm{z}}[\mu \mathrm{m}]$ & $\mathrm{R}_{\mathrm{q}}[\mu \mathrm{m}]$ & $\mathrm{R}_{\mathrm{t}}[\mu \mathrm{m}]$ \\
& 1 & 7.73 & 49.32 & 10.20 & 68.86 \\
01 & 2 & 4.83 & 35.83 & 6.62 & 48.83 \\
& 3 & 5.59 & 33.25 & 7.27 & 50.85 \\
& 4 & 7.58 & 43.21 & 9.54 & 50.10 \\
& 5 & 6.31 & 33.02 & 7.76 & 49.84 \\
02 & 1 & 6.35 & 37.40 & 7.88 & 52.87 \\
& 2 & 9.06 & 46.68 & 11.03 & 65.81 \\
& 3 & 7.51 & 41.13 & 9.28 & 69.59 \\
& 4 & 9.57 & 54.43 & 12.26 & 67.15 \\
03 & 5 & 5.71 & 42.17 & 8.32 & 70.18 \\
& 1 & 5.14 & 32.63 & 6.68 & 54.78 \\
& 2 & 5.13 & 35.35 & 6.77 & 50.88 \\
& 3 & 3.99 & 29.30 & 5.58 & 51.61 \\
& 4 & 7.28 & 41.29 & 9.07 & 64.68 \\
& 5 & 7.27 & 48.08 & 9.74 & 67.55 \\
\hline
\end{tabular}

Table 4: Surface roughness measurements.
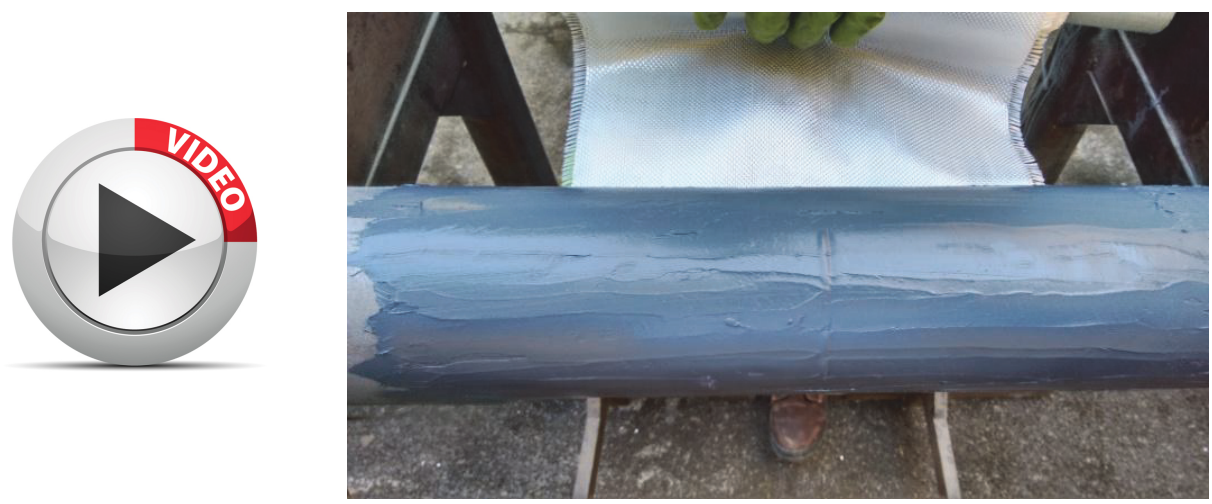

Figure 4: Primer Layer.

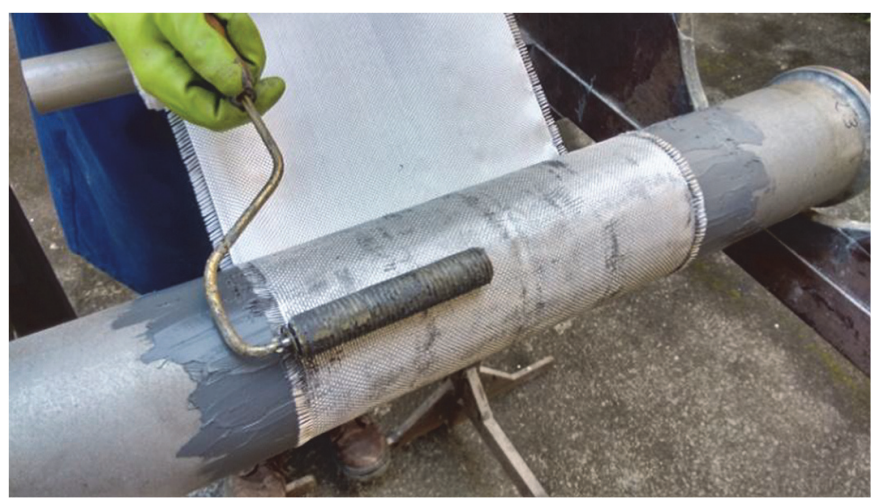

Figure 5: Pre-impregnated, bi-directional composite. 


\section{Hydrostatic Testing}

The hydrostatic tests were performed in the bunker at room temperature condition. The specimen used in the hydrostatic test is presented in Fig.6. For the hydrostatic test, the Flutrol's Test Pac equipment was used. The pressure was increased by approximately $1 \mathrm{bar} / \mathrm{second}$ and after reaching a certain level, the pressure was maintained for 30 minutes. Then again raised by $1 \mathrm{bar} / \mathrm{second}$ up to next level, until the repair system fails. Load the tube specimen for $30 \mathrm{~min}$ at a particular operating pressure and then increased for next pressure level. Each test shall be monitored by a PID system to record the test results.

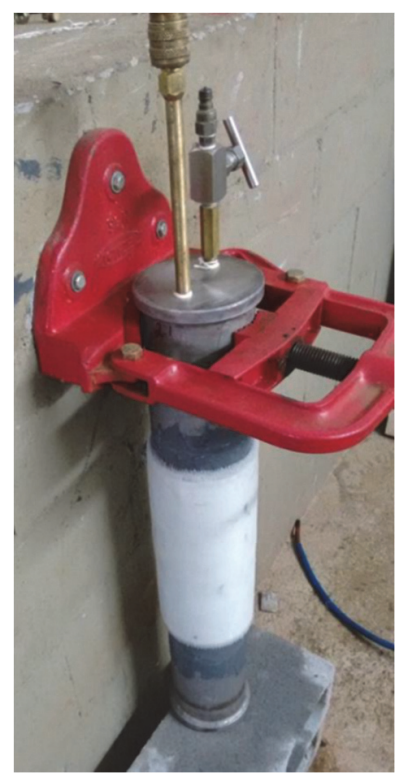

Figure 6: Hydrostatic testing.

\section{RESUlTS AND DisCussions}

7 ab. 5 shows the failure pressure by the tube specimen with through thickness defect $25 \%, 50 \%$ and $96 \%$ of the perimeter. All three through-thickness defect $(25 \%, 50 \%$ and $96 \%$ of the perimeter) specimens sustained a calculated design pressure of $4 \mathrm{MPa}$. The failure pressure of the specimen (i) with a through-thickness defect in $25 \%$ of the perimeter was $9.5 \mathrm{MPa}$. The tube specimen resisted constant pressure of $3 \mathrm{MPa}, 6 \mathrm{MPa}$ and $9 \mathrm{MPa}$ for 30 min each for the specimen with $25 \%$ through thickness defect. The tube specimen with a through thickness defect in $50 \%$ of the perimeter resisted constant pressures of $2 \mathrm{MPa}, 4 \mathrm{MPa}$ and $6 \mathrm{MPa}$. However, it fails at higher pressure at $10 \mathrm{MPa}$. The failure pressure of the specimen with a through thickness defect in $96 \%$ of the perimeter was $8.5 \mathrm{MPa}$, which is lower than the failure pressure observed for the other two defects, as expected. Pipe failure was considered when a fluid leaking was observed between the pipe and the composite or when the pressure dropped suddenly.

\begin{tabular}{cccc}
\hline & $\begin{array}{c}\text { Through thickness defect } \\
\text { in } 25 \% \text { of the perimeter }\end{array}$ & $\begin{array}{c}\text { Through thickness defect } \\
\text { in } 50 \% \text { of the perimeter }\end{array}$ & $\begin{array}{c}\text { Through thickness defect in } \\
96 \% \text { of the perimeter }\end{array}$ \\
\hline $\begin{array}{c}\text { Specimen Failure } \\
\text { pressure }\end{array}$ & $9.5 \mathrm{MPa}$ & $10 \mathrm{MPa}$ & $8.5 \mathrm{MPa}$ \\
\hline
\end{tabular}

Table 5: Failure pressure in the tests.

It has been observed that the failure pressure of the pipe with a $25 \%$ through thickness defect is lower than the one with higher through thickness defect 50\%. The same trend has also been observed by Watanabe Junior et al. [11], pipe fails at lower pressure for smaller defects than the bigger defect in pipe. It is known from practical applications that to avoid leaking through a small defect in a pipe, conveying a liquid under high pressure can be sometimes more difficult than in the case of 
a bigger defect. The design of composite repairs must also take into account the strength of the interface adhesion between composite and metal [33]. The main result is that the repair system can resist to elevated pressures even with a complete $(96 \%)$ through-wall defect. Hence this composite repair system can avoid unexpected failure and also premature failure of the pipe, which help to extend the maintenance deadline. The effectiveness of the repair depends on several factors such as: the composite properties, thickness and length, the surface preparation, the adhesion between the pipe and composite layers, etc. Therefore, it is important to study the composite repair performance, subjected to different parameters such as composite repair material, repair thickness, surface preparation, etc.

\section{CONCLUSIONS}

7 he use of polymer-based composite systems to repair metallic pipes with localized corrosion damage has been widely used in the offshore and onshore units, as it is more suitable and economical than the others maintenance alternatives. This study evaluates the effectiveness of composite repair on severely corroded circumferential welds in super duplex stainless steel pipes. This problem can be eliminated using a polymer-based composite system to repair and reinforce the corroded welds. It is suggested to apply the composite sleeve over the weld bead as a precaution to assure that pipe can operate safely until the next planned maintenance stop, even in the case of through- thickness corrosion damage. The present study verified that the polymer-based composite can effectively avoid leaking in the case of through thickness damage. The present composite repair system sustained the design pressure for the nearly complete $(96 \%)$ through thickness defect corroded pipe. The results conclude that this methodology can be used in weld joints presenting damage of throughwall defects up to $96 \%$ of the perimeter of the pipe. Therefore, it can assure the pipe operation during the progression of the corrosion and also when the through thickness metal loss is verified, if the reinforcement system is used as a preliminary and additional measure to protect the welds. In addition, it can maintain an adequate level of mechanical strength for a given operating pressure and can prevent leakage until a planned maintenance of the unit.

\section{ACKNOWLEDGEMENTS}

he authors would like to acknowledge Petrobras and the support of the Brazilian research agencies CNPQ, CAPES and FAPERJ.

\section{REFERENCES}

[1] Chen, Y., Zhang, H., Zhang, J., Liu, X., Li, X., Zhou, J., (2015). Failure assessment of X80 pipeline with interacting corrosion defects, Eng. Fail. Anal., 47, pp. 67-76. https://doi.org/10.1016/j.engfailanal.2014.09.013.

[2] Comanescu, I., Melchers, R.E., Taxén, C. (2016). Corrosion and durability of offshore steel water injection pipelines, Ships Offshore Struct., 11(4), pp. 424-437. https://doi.org/10.1080/17445302.2015.1014249.

[3] Saliba, P.A., Mansur, A.A., Santos, D.B., Mansur, H.S. (2015). Fusion-bonded epoxy composite coatings on chemically functionalized API steel surfaces for potential deep-water petroleum exploration, Applied Adhesion Science, 3(1), 22. https://doi.org/10.1186/s40563-015-0052-2.

[4] Goertzen, W.K., Kessler, M.R. (2007). Dynamic mechanical analysis of carbon/epoxy composites for structural pipeline repair. Compos Part B-Eng. 38(1), pp.1-9. https://doi.org/10.1016/j.compositesb.2006.06.002.

[5] De Barros, S., Meniconi, L.C.M., Perrut, V.A., de Siqueira, C.E.R. (2017) Oil Industry. In: da Silva L., Öchsner A., Adams R. (eds) Handbook of Adhesion Technology. Springer, Cham. https://doi.org/10.1007/978-3-319-42087-5_60-1.

[6] De Barros, S., Banea, M.D., Budhe, S., De Siqueira, C.E.R., Lobão, B.S.P., Souza, L.F.G. (2017). Experimental analysis of metal-composite repair of floating offshore units (FPSO), J. Adhes., 93(1-2), pp. 147-158. https://doi.org/10.1080/00218464.2016.1177514.

[7] Perren, R.A., Suter, T.A., Uggowitzer, P.J., Weber, L., Magdowski, R., Bohni, H., Speidel, M.O. (2001). Corrosion resistance of super duplex stainless steels in chloride ion containing environments: investigations by means of a new microelectrochemical method I. Precipitation-free states, Corros. Sci., 43(4), pp. 707-726. https://doi.org/10.1016/S0010-938X(00)00087-1. 
[8] Elhoud, A.M., Renton, N.C., Deans, W.F. (2011). The effect of manufacturing variables on the corrosion resistance of a super duplex stainless steel. Int. J. Adv. Manuf. Technol., 52(5-8), pp. 451-461.

https://doi.org/10.1007/s00170-010-2756-6.

[9] Pardal, J.M., Tavares, S.S.M., Fonseca, M.P.C., Souza, J.A., Vieira, L.M., Abreu, H.F.G. (2010). Deleterious phases precipitation on superduplex stainless steel UNS S32750: characterization by light optical and scanning electron microscopy, Mater. Res., 13(3), pp. 401-407. http:/ /dx.doi.org/10.1590/S1516-14392010000300020.

[10] Qiao, Q., Cheng, G., Wu, W., Li, Y., Huang, H., Wei, Z. (2016). Failure analysis of corrosion at an inhomogeneous welded joint in a natural gas gathering pipeline considering the combined action of multiple factors, Eng. Fail.Anal.64(2016), pp.126-143. https://doi.org/10.1016/j.engfailanal.2016.02.015.

[11] Watanabe, Junior. M.M., Reis, J.M.L., da Costa Mattos, H.S. (2017). Polymer-based composite repair system for severely corroded circumferential welds in steel pipes, Eng. Fail. Anal., 81(2017), pp. 135-144. https://doi.org/10.1016/j.engfailanal.2017.08.001.

[12] Seica, M.V., Packer, J.A. (2007). FRP materials for the rehabilitation of tubular steel structures for under water applications, Compos. Struct. 80(3), pp. 440-450. https://doi.org/10.1016/j.compstruct.2006.05.029.

[13] Cuthill, J. (2002) Advances in materials, methods, help gain new users, Pipeline Gas J., 229(11), pp. 64-66.

[14] Marsh, G. (2004). Composites renovate deteriorating sewers, Reinforced Plastics., 48(6), pp. 20-24. https://doi.org/10.1016/S0034-3617(04)00338-8.

[15] Teixeira de Freitas, S, Banea, M.D., Budhe, S., de Barros, S. (2017). Interface adhesion assessment of composite-tometal bonded joints under salt spray conditions using peel tests, Compos. Struct., 164, pp. 68-75. https://doi.org/10.1016/j.compstruct.2016.12.058.

[16] ASME PCC-2, Repair of pressure equipment and piping, Nonmetallic and Bonded Repairs, The American Society of Mechanical Engineers, 2011.

[17] ISO 24817, ISO International Organization for Standardization. Petroleum, petrochemical and natural gas industries Composite repairs for pipework - Qualification and design, installation, testing and inspection. 2017.

[18] Toutanji, H., Dempsey, S. (2001) Stress modeling of pipelines strengthened with advanced composite material. Thin Wall Struct.39(2), pp.153-165. https://doi.org/10.1016/S0263-8231(00)00049-5.

[19] Wilberforce, S., Hashemi, S. (2009) Effect of fibre concentration, strain rate and weldline on mechanical properties of injection-moulded short glass fibre reinforced thermoplastic polyurethane. J. Mater. Sci., 44(5), pp. 1333-1343. https://doi.org/10.1007/s10853-008-3233-6.

[20] Rohem, N.R.F., Pacheco, L.J.,Budhe, S.,Banea, M.D.,Sampaio, E.M., de Barros, S. (2016) Development and qualification of a new polymeric matrix laminated composite for pipe repair, Compos. Struct., 152, pp. 737-745. https://doi.org/10.1016/j.compstruct.2016.05.091.

[21] da Costa Mattos, H.S., Reis, J.M.L., Sampaio, R.F., Perrut, V.A. (2009). An alternative methodology to repair localized corrosion damage in metallic pipelines with epoxy resins, Mater. Des., 30(9), pp. 3581-3591. https://doi.org/10.1016/j.matdes.2009.02.026.

[22] da Costa Mattos, H.S., Paim, L.M., Reis, J.M.L. (2012). Analysis of burst tests and long-term hydrostatic tests in produced water pipelines, Eng. Fail. Anal., 22, pp. 128-140. https://doi.org/10.1016/j.engfailanal.2012.01.011.

[23] da Silva, M.L., da Costa Mattos, H.S. (2013) Failure pressure estimations for corroded pipelines, Mater. Sci. Forum., 758, pp. 65-76. https://doi.org/10.4028/www.scientific.net/MSF.758.65.

[24] da Costa Mattos, H.S., Reis, J.M.L., Paim, L.M., da Silva, M.L., Amorim, F.C., Perrut, V.A. (2014) Analysis of a glass fibre reinforced polyurethane composite repair system for corroded pipelines at elevated temperatures, Compos. Struct., 114, pp. 117-123. https://doi.org/10.1016/j.compstruct.2014.04.015.

[25] da Costa Mattos, H.S., Reis, J.M.L., Paim, L.M., da Silva, M.L., Lopes, Junior. R., Perrut, V.A. (2016). Failure analysis of corroded pipelines reinforced with composite repair systems, Eng. Fail. Anal. 59, pp. 223-236. https://doi.org/10.1016/j.engfailanal.2015.10.007.

[26] Budhe, S., Banea, M.D., Rohem, N.R.F., Sampaio, E.M., de Barros, S., (2017). Failure pressure analysis of composite repair system for wall loss defect of metallic pipelines, Compos. Struct. 176, pp. 1013-1019. https://doi.org/10.1016/j.compstruct.2017.06.044.

[27] Shamsuddoha, M.D., Mainul, I.M., Aravinthan, T., Manalo, A., Lau, K. (2013). Effectiveness of using fibre-reinforced polymer composites for underwater steel pipeline repairs, Compos. Struct., 100, pp. 40-54. https://doi.org/10.1016/j.compstruct.2012.12.019.

[28] Duell, J.M., Wilson, J.M., Kessler, M.R. (2008). Analysis of a carbon composite overwrap pipeline repair system, Int. J. Pres. Ves. Pip., 85(11), pp. 782-788. https://doi.org/10.1016/j.ijpvp.2008.08.001. 
[29] Saeed, N., Ronagh, H., Virk, A. (2014). Composite repair of pipelines, considering the effect of live pressure-analytical and numerical models with respect to ISO/TS 24817 and ASME PCC-2, Compos. Part B-Eng., 58(2014), pp. 605-610. https://doi.org/10.1016/j.compositesb.2013.10.035.

[30] ASTM D3039, Standard test method for tensile properties of polymer matrix composite materials, 2011.

[31] Costa H.R.M., Reis J.M.L., Souza J.P.B., Pacheco P.M.C.L., Aguiar R.A.A., De Barros S. (2015). Experimental investigation of the mechanical behaviour of spot welding-adhesives joints, Compos. Struct., 133, pp. 847-852. https://doi.org/10.1016/j.compstruct.2015.08.036.

[32] De Barros, S., De Souza, J.R., Gomes, K.C., Sampaio, E.M., Barbosa, N.P., Torres, S.M. (2012) Adhesion of geopolymer bonded joints considering surface treatments. J. Adhes., 88(4-6), pp. 364-375. https://doi.org/10.1080/00218464.2012.660075.

[33] Linden, J.M., Kotsikos, G., Gibson, A.G. (2016). Strain energy release rate in shaft-loaded blister tests for composite repairs on steel, Compos. Part A-Appl. S., 81(2016), pp. 129-138. https://doi.org/10.1016/j.compositesa.2015.10.026. 